\title{
Material Removal Mechanism of Green Machining on Powder Metallurgy Parts during Orthogonal Cutting
}

\author{
Dayong Yang $\mathbb{D}^{1},{ }^{1}$ Longsheng $\mathrm{Lu}^{2}$ and Zhenping Wan $\mathbb{D i D}^{2}$ \\ ${ }^{1}$ School of Mechanical and Transportation Engineering, Guangxi University of Science and Technology, Liuzhou 545006, China \\ ${ }^{2}$ School of Mechanical and Automotive Engineering, South China University of Technology, Guangzhou 510640, China \\ Correspondence should be addressed to Zhenping Wan; zhpwan@scut.edu.cn
}

Received 15 February 2020; Revised 17 May 2020; Accepted 25 June 2020; Published 13 July 2020

Academic Editor: Francesco Ruffino

Copyright ( 2020 Dayong Yang et al. This is an open access article distributed under the Creative Commons Attribution License, which permits unrestricted use, distribution, and reproduction in any medium, provided the original work is properly cited.

Due to its energy-saving and cost-reducing characteristics, a novel green machining technique for powder metallurgy (PM) parts is attracting increasing concern. Unlike in the traditional PM machining technique, in the PM green-machining method arranges, the processing operation is performed before sintering. Since the pristine PM compacts are relatively soft because it just bonds the particles together, direct cutting on pristine PM compacts is a tool-saving and cost-effective manufacturing technique and its cutting mechanism is different from that of both solid plastic metals and conventional brittle materials because of the special characteristics of a discontinuous material. The influences of cutting parameters on machined surface roughness are investigated by orthogonal cutting experiments. The results show that the machined surface roughness decreases with increasing cutting thickness and rounded cutting edge radius and slightly increases with increasing rake angle. It is suggested that these results are contrary to the long-held notions of machined surface roughness. Moreover, a geometric model illustrating the PM greenmachining process was established to reveal the mechanism of material removal and machined surface formation. This model shows that the material removal of PM is composed of particle shearing deformation, peeling, and ploughing/extruding. Finally, this machining model was validated through observations of machined surface morphology and chip morphology.

\section{Introduction}

PM components have been widely used in several industrial fields, such as the automobiles [1], aerospace [2], military products [3], and healthcare [4] industries. Generally, PM is assumed to be a near-net shape process which means that the additional shaping operations, such as machining, are unnecessary [5]. However, for parts with high precision and complex structures, such as threads and holes perpendicular to the pressing axis, subsequent machining operations are essential and effective [6]. Therefore, more than $40 \%$ of PM components in industrial products must be machined to meet design requirements [7, 8]. However, the hard particles that are randomly distributed in sintered PM components cause severe abrasive wear of tools [9]. In addition, the microvibrations during cutting and the low thermal conductivities of sintered PM components due to their internal porosities will facilitate the further tool wear [10]. M'Saoubi et al. [11] addressed the machinability of PM high-speed steels during longitudinal and orthogonal hard turning. Their results show that severe tool wear occurs when the cutting length is only $25 \mathrm{~m}$ at a cutting speed of $150 \mathrm{~m} / \mathrm{min}$. Therefore, with the development of sophisticated and complex PM component processing techniques, a way to improve the machinability of PM components must be identified.

Green machining for PM components (defined as PM green machining) is a novel and prospective manufacturing technique that could overcome the aforementioned problems and greatly enhance the machining efficiency [12]. During the green machining process, most subsequent machining operations are performed before sintering.

The material powder or particles are pressed together by cold welding, bonding, and mechanical interlocking, and the green compacts contain no hard particles. Therefore, there occurs little tool wear during green machining. 
Furthermore, according to Desbiens et al. [13], interestingly, both the yield strength and ultimate strength of sintered PM components are increased by $18 \%$ and $9 \%$, respectively, when machined in the green state. In addition, RobertPerron et al. [14] found that PM components prepared by green machining followed by sintering were accurate enough to meet requirements because only $0.33 \%$ dimensional variation was measured after sintering. In addition, the chips of green machining can be recycled directly for cyclic utilization because their size is similar to that of the base powders [15]. Consequently, PM green machining has been a hot topic in both industry and research. RobertPerron et al. [16] presented an experimental investigation on the turning of a groove on an automobile timing sprocket made from PM material in the green state. Their results revealed that the average width of breakouts increases with the PM porosity and that the variation in the breakout width is very sensitive to the cutting parameters. They also conducted drilling experiments on green PM components [17]. Their results illustrated that the minimum width of breakouts would be obtained when the KWCD00461 drill type and $0.0254 \mathrm{~mm} / \mathrm{r}$ feed rate were used. Gagne and Chagnon [18] discussed the machinability of green PM components. Their results show that the feed rate had a significant effect on the breakouts that occurred at the exit of the tool. A crucial problem encountered during PM green machining is the very low strength of the green compacts, which sometimes cannot bear the cutting force resulting in aborted machining operations. Due to this defect, it is difficult to obtain a low surface roughness, with the current green machining techniques, and the components machined on green compacts are mainly used for parts with low precision requirements, such as pillars, brackets, repair sleeves, shafts, and covers. Because the components machined on green compacts do not need secondary processing after sintering, the good quality of a green machined surface has an important impact on the actual production. Therefore, the roughness of a green machined surface must be further reduced to meet the accuracy requirements of components in a larger range. To improve the green strength and thus improve the machined surface quality, Tremblay et al. [19, 20] and Chagnon et al. [21] developed new polymeric binder/lubricant systems that could greatly enhance the green strength of PM compacts.

On the whole, previous studies on PM green machining focus on the influence of cutting parameters on breakouts and the improvement in machinability. The mechanism of material removal during PM green machining has not been fully investigated. This work established a geometric model to reveal the mechanism of material removal during PM green machining. Experiments were conducted to validate this model.

\section{Experimental Procedures}

2.1. Material Preparation. It can be predicted that a higher green strength is more conducive to achieving a better machining quality. There are several processes that are utilized to increase green strength. The most effective method is presintering. However, presintering is expensive and has a narrow application range in engineering. The warm compaction technique, with the advantages of wide application range and low cost, is another effective method used to increase green strength. To make this research more consistent with an actual project, green compacts were prepared by the warm compaction technique.

A set of ferrous green compact specimens was prepared in a mold, where the metal powders and die walls were preheated at a temperature of $120^{\circ} \mathrm{C}$. The material composition and particle size, which are provided by the producer, are listed in Tables 1 and 2, respectively. As shown in Table 2, the diameters, $48.4 \%$ of the particles, are between $120 \mu \mathrm{m}$ and $75 \mu \mathrm{m}$. The dimensions of the specimens were $37 \mathrm{~mm} \times 49 \mathrm{~mm} \times 10 \mathrm{~mm}$. The microstructure of the green compacts is shown in Figure 1. It can be seen that the green compacts contain many ferrous particles and numerous very small pores. The boundaries between most particles were clear, indirectly indicating that the bonding strength among particles is low. Tensile tests were carried out according to the MPIF (Metal Powder Industries Federation) Standard. The results suggest that the tensile strength and green strength were less than $5 \mathrm{MPa}$ and $15 \mathrm{MPa}$, respectively. The Vickers hardness of the green compacts was less than $110 \mathrm{HV} / 0.5$, i.e., the green compacts are quite soft compared with common solid metals.

2.2. Experimental Steps. Dry orthogonal cutting experiments were performed on a BC6063B planer to validate the model of PM green machining. The experimental setup is shown in Figure 2. The work pieces were green compacts with a width of $10 \mathrm{~mm}$ and a green density of $7.1 \mathrm{~g} / \mathrm{cm}^{3}$. The self-designed cutting tools with a width of $14 \mathrm{~mm}$ were made of high-speed steel with a clearance angle of $20^{\circ}$ and rake angle of $10^{\circ}$, except for the experiments of the influence of rake angle on machined surface roughness. The cutting speed was set to $5 \mathrm{~m} / \mathrm{min}$. The roughness of the machined surface was measured by an SMS Optical Measurement Station, and the test direction was consistent with the cutting direction. To minimize experimental errors, each experiment was repeated five times, and the average value was taken as the final result.

\section{Influence of Cutting Parameters on Machined Surface Roughness}

The influence of cutting thickness on machined surface roughness at a rounded edge radius of $20 \mu \mathrm{m}$ is shown in Figure 3(a). It is worth noting that as the cutting thickness increases, the machined surface roughness significantly decreases. Clearly, this behavior is contrary to the existing cutting theory related to solid metal cutting in which the increase in cutting thickness leads to high surface roughness and poor surface quality.

To analyze machined surface quality at different rounded edge radii, special cutting tools, with $10^{\circ}$ rake angles and a set of rounded edge radii of $20 \mu \mathrm{m}, 40 \mu \mathrm{m}, 60 \mu \mathrm{m}, 90 \mu \mathrm{m}$, and $120 \mu \mathrm{m}$, were prepared. Figure 3(b) presents the effect of the 
TABle 1: Composition of the green compacts.

\begin{tabular}{lcccccc}
\hline Composition & Graphite & Molybdenum & Nickel & Copper & Paraffin & Iron \\
\hline Percentage (\%) & 0.3 & 0.5 & 1.75 & 1.5 & 0.6 & Others \\
\hline
\end{tabular}

TABle 2: Size distribution of the particles.

\begin{tabular}{lcccc}
\hline Particle size & $120 \sim 75 \mu \mathrm{m}$ & $75 \sim 62 \mu \mathrm{m}$ & $62 \sim 45 \mu \mathrm{m}$ & $<45 \mu \mathrm{m}$ \\
\hline Percentage (\%) & 48.4 & 13.05 & 15.4 & 21.44 \\
\hline
\end{tabular}

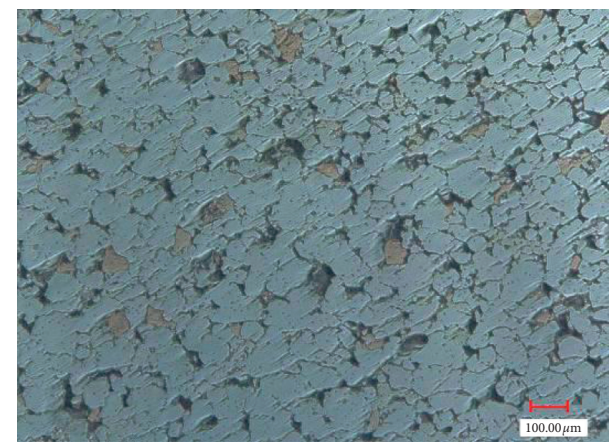

FIgURE 1: Microstructure of the green compacts.

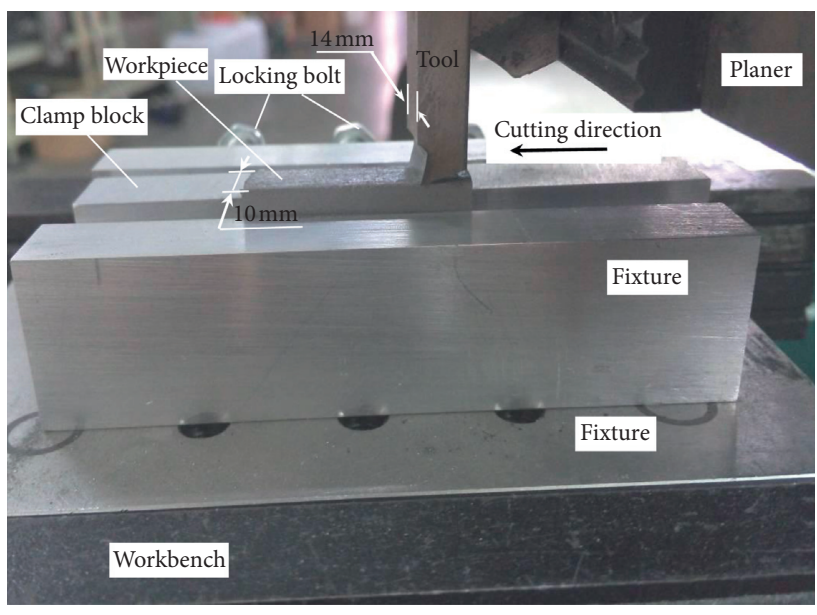

Figure 2: Orthogonal cutting experiment device.

rounded cutting edge radius on the machined surface roughness when the cutting thicknesses are $0.1 \mathrm{~mm}$ and $0.2 \mathrm{~mm}$. It can be seen that, with the increase in rounded cutting edge radius, the machined surface roughness significantly decreases when the rounded cutting edge radius is less than $60 \mu \mathrm{m}$ and then slowly decreases with the continuous increase in rounded cutting edge radius. Considering the long-held notion that surface quality will deteriorate with increasing rounded cutting edge radius due to ploughing and extrusion, the varied trend in the green machining of PM components is novel. A similar trend was observed in the machinability of polycrystalline materials: according to the research on the machining mechanism of coarse-grained polycrystalline $\mathrm{ZnSe}$ investigated by Huang et al. [22], a larger tool nose radius (not cutting edge radius) is beneficial to eliminate machined surface defects.
Figure 3(c) shows the machined surface roughness obtained at different rake angles when the cutting thickness is $0.2 \mathrm{~mm}$ and rounded cutting edge radius is between $15 \mu \mathrm{m}$ and $25 \mu \mathrm{m}$. As shown in Figure 3(c), although there is a significant fluctuation among the machined surface roughnesses when the rake angle increases from $-20^{\circ}$ to $20^{\circ}$, it can be seen from the linear fitting of the roughness values at different rake angles that, with the increase in the rake angle, the machined surface roughness slightly increases.

Overall, the influences of cutting thickness, rake angle, and rounded cutting edge radius on the machined surface roughness and the cutting process of green compacts are obviously different from those of conventional brittle and plastic materials.

\section{Geometric Model of the Cutting Process}

4.1. Representative Machined Surface Morphologies. Figure 4 shows the machined surface morphologies of green PM compacts obtained with a rounded edge radius of $20 \mu \mathrm{m}$ and cutting thicknesses of $0.1 \mathrm{~mm}$ and $0.2 \mathrm{~mm}$. From Figure 4 , the large number of plastic trails due to material removal is quite distinct. It is proven that the particles are cut plastically by shear deformation. In addition, there are many tiny concavities and crevices. In light of the size of the concavities, these concavities and crevices are likely formed from small particles peeling off due to an insufficient bonding strength. When some particles that possess low bonding strength with other adjacent particles are cut or extruded by the cutting tool, these particles will become loose and crevices form. Furthermore, some borders of particles cut by tool are overlapped. The overlapped borders are formed by the ploughing and extruding of the tool.

It should be noted that the machined surface morphology of PM green compacts shown in Figure 4 is similar to the machined surface morphology of coarse-grained polycrystalline ZnSe during the ultraprecision diamond turning process, which also shows evidence of shear deformation and many concavities with different sizes [22]. The later forming process of the smaller concavities is similar to the forming process of the concavities on the surface of machined PM green compacts, which are caused by the peeling of the material, while the later larger concavities are caused by crack propagation, which is a process significantly different from the formation of the concavities on the machined surface of the PM green compacts.

4.2. Establishment of the Geometric Model for the PM GreenMachining Process. The above analysis suggests that the machined surface of green PM compacts exhibits a plastically deformed surface produced by particle shearing or ploughing/extruding, as well as concavities and crevices. Correspondingly, there are three main modes of material 

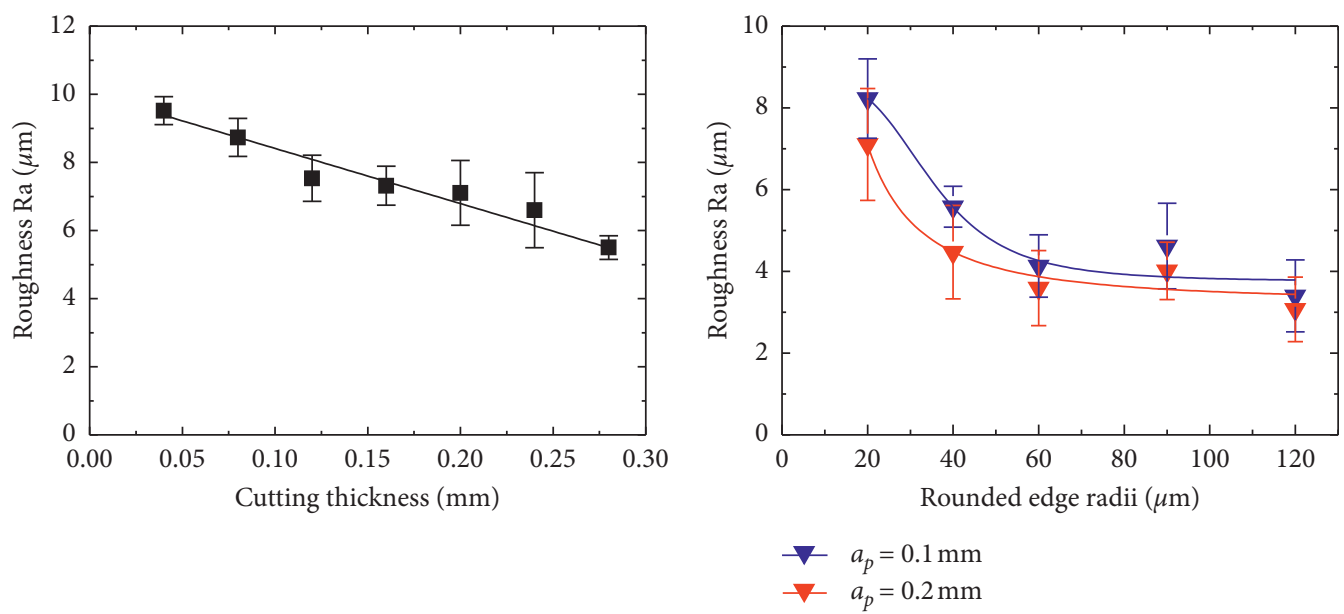

(a)

(b)

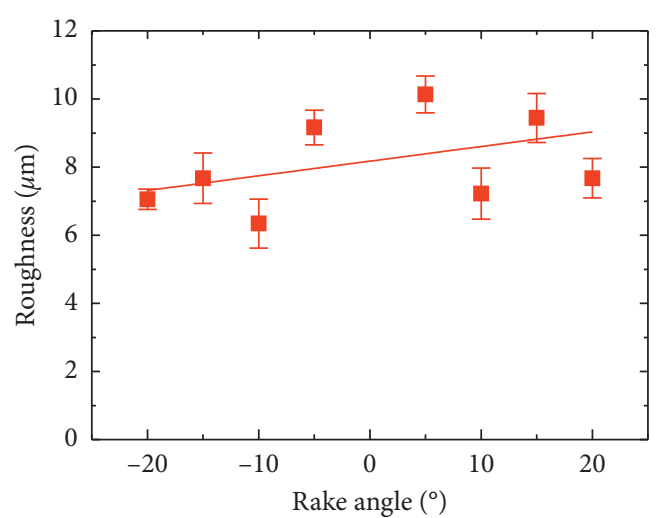

(c)

Figure 3: Influence of (a) cutting thickness, (b) rounded edge radius, and (c) rake angle on machined surface roughness.

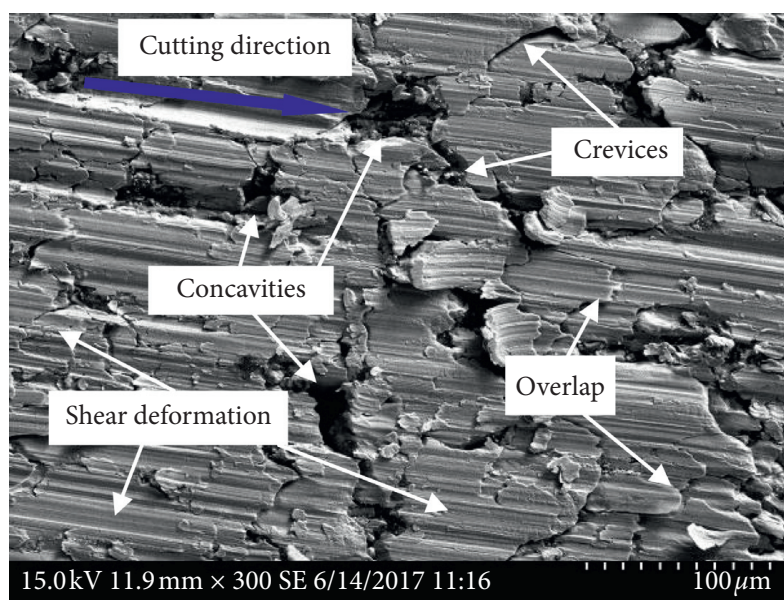

(a)

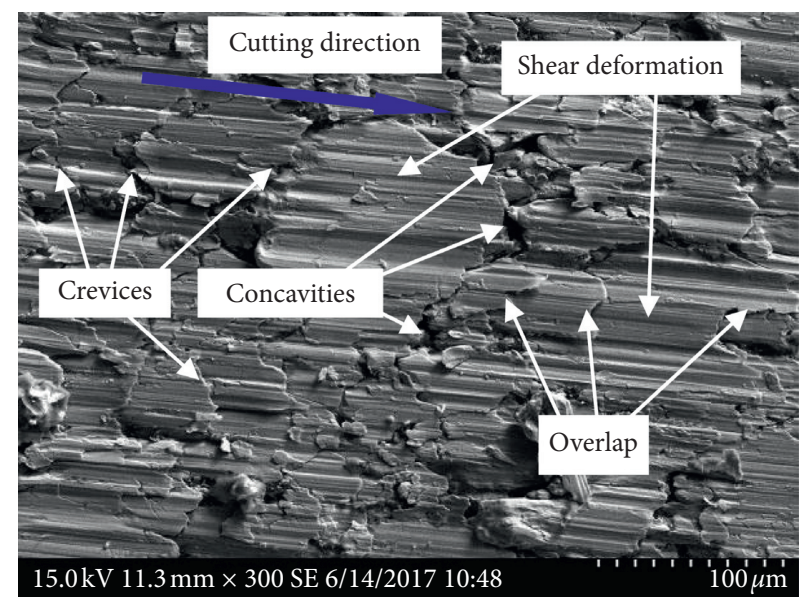

(b)

Figure 4: Machined surface morphology corresponding to thicknesses of (a) $0.1 \mathrm{~mm}$ and (b) $0.2 \mathrm{~mm}$.

removal, including particle shearing, peeling off, and ploughing/extruding. Based on the analysis, a geometric model of the PM green-machining process is established, as presented in Figure 5. In this model, several affecting factors are taken into account for the machined surface formation, which are the rounded cutting edge radius, cutting thickness, particle size, and relative position between the cutting edge and particles. When a particle body is mainly located above the stagnation point of the cutting edge, this particle will be peeled off due to the insufficient bonding strength, and then 


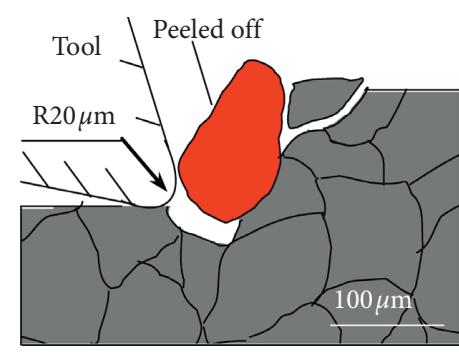

(a)

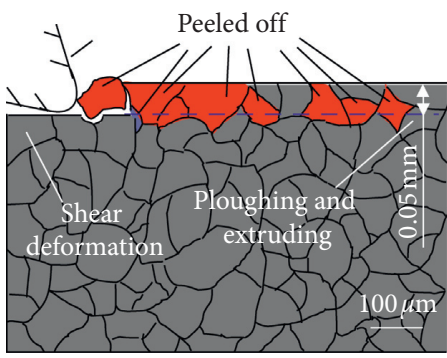

(d)

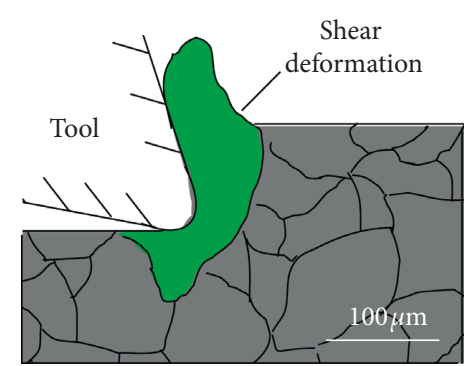

(b)

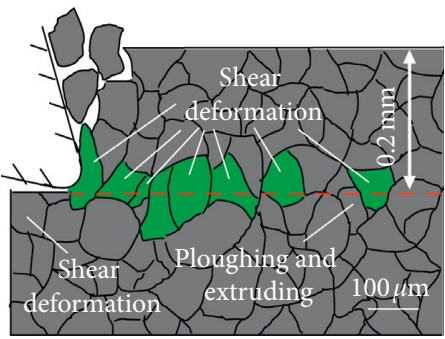

(e)

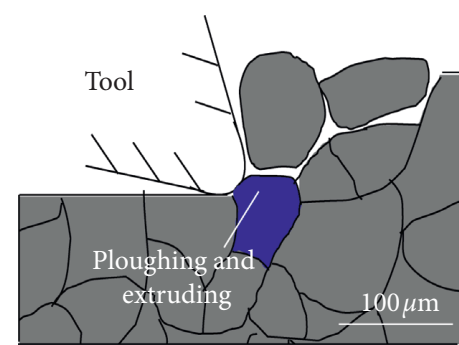

(c)

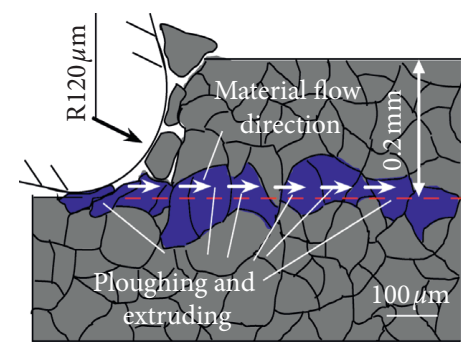

(f)

FiguRE 5: Material removal model of (a) peeled off, (b) shear deformation, and (c) ploughing and extruding. The formation process of the machined surface when the rounded edge radius is $20 \mu \mathrm{m}$ and cutting thickness is (d) $0.05 \mathrm{~mm}$ or (e) $0.2 \mathrm{~mm}$, respectively. (f) The formation process of the machined surface at a rounded edge radius of $120 \mu \mathrm{m}$ and cutting thickness of $0.2 \mathrm{~mm}$.

a concavity is generated in the machined surface, as shown in Figure 5(a). When half of a particle body is located above the stagnation point of the cutting edge, this particle may be plastically cut into two pieces and integrated surface and plastic trails are formed, as shown in Figure 5(b). If a particle body is entirely located below the stagnation point of the cutting edge, the material removal is mainly in terms of ploughing and extruding which results in the overlap of the particle boundaries. As such, the machined surface quality is improved, as shown in Figure 5(c). Under the comprehensive action of the aforementioned three modes of PM material removal, some additional crevices around particles may emerge on the machined surface under the cutting force due to the weak link between the particles.

Since particles with different sizes inside the green PM compact are randomly distributed, the relative positions between the cutting edge and particles are also random. In fact, the particle size is one of the factors that affect the material removal mechanisms: when the rounded cutting edge radius is constant, the particle size will affect the relative position between the particle and the stagnation point of the cutting edge and then affect the material removal process. Therefore, the three material removal modes coexist during the PM green-machining process. Furthermore, the proportion of each material removal mode changes with the cutting parameters. Figure $5(\mathrm{~d})$ shows the material removal process when the cutting thickness is $0.05 \mathrm{~mm}$ and the rounded edge radius is $20 \mu \mathrm{m}$. The particle peeling off action is predominant because over half of the particles in the cutting layer are approximately $0.05 \mathrm{~mm}$. As the cutting thickness increases, it can be inferred that particle shearing gradually dominates because the particles that peeled off with a very small cutting thickness will be plastically cut off, as shown in Figure 5(e). In this case, the machined surface roughness will be improved. The proportion of ploughing and extruding increases with increasing rounded cutting radius until it accounts for the vast majority of material removal modes, as shown in Figure 5(f).

4.3. Model Validation. Based on the model of the PM greenmachining process described above, the machined surface is composed of randomly repeating plastically deformed surfaces, concavities, and crevices. Furthermore, if the rounded cutting edge radius is large enough, the modes of particle ploughing and extruding are completely predominant. These processes can be validated by the machined surface and chip morphologies.

\subsubsection{Model Validation in Terms of Machined Surface Morphology}

(1) Machined Surface Morphology Obtained at Different Rounded Cutting Edge Radii. Figure 6 demonstrates the surface morphologies machined at different rounded edge radii when the cutting thickness is $0.2 \mathrm{~mm}$. When the cutting edge radius is $20 \mu \mathrm{m}$, the surface materials are removed mainly by shearing and peeling off because the machined surface is composed of a plastically deformed surface and concavities, as shown in Figure 6(a). When the rounded cutting edge radius is $40 \mu \mathrm{m}$, the surface materials are removed mainly by ploughing and extruding, as shown in Figure 6(b), and the machined surface roughness decreases. When the rounded cutting edge radius is $120 \mu \mathrm{m}$, the machined surface forms by ploughing and extruding by the cutting edge, even though the pores contained in the 


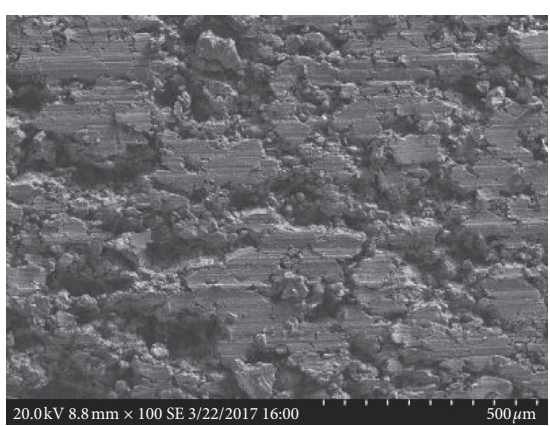

(a)

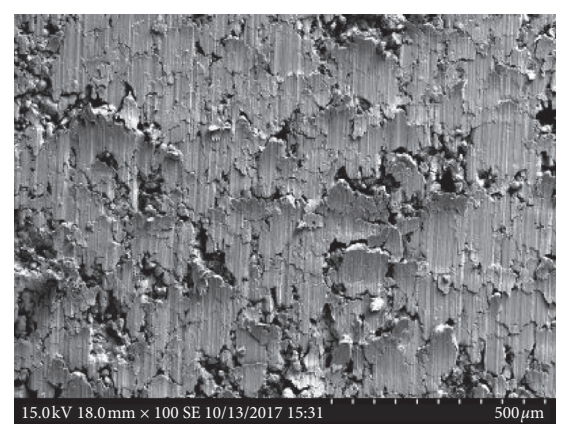

(b)

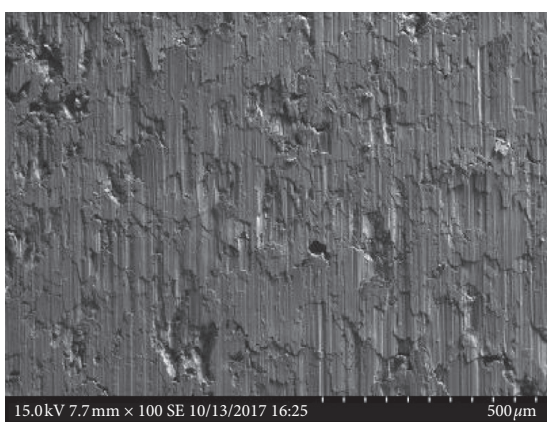

(c)

FIGURE 6: Machined surface morphologies machined at rounded edge radius of (a) $20 \mu \mathrm{m}$, (b) $40 \mu \mathrm{m}$, and (c) $120 \mu \mathrm{m}$.

material are filled up, and then, the machined surface roughness is further decreased, as shown in Figure 6(c). This conforms to the model of the PM green-machining process, as shown in Figure 4, and effectively illustrates the varied trend of machined surface roughness with the rounded cutting edge radius, as presented in Figure 3(b). Therefore, the model of the PM green-machining process is validated by the machined surface morphologies obtained at different rounded cutting edge radiuses.

\section{(2) Machined Surface Morphology Obtained at Different} Cutting Thicknesses. Figure 7 shows the morphologies of machined surfaces obtained at a cutting thickness of $0.05 \mathrm{~mm}$ and rounded edge radius of $20 \mu \mathrm{m}, 0.14 \mathrm{~mm}$, and $0.26 \mathrm{~mm}$. Figure 7 (a) shows that the formation mechanism of the machined surface is mainly due to particle peeling off, which agrees well with the theoretical predictions in Figure 5(d). Figures 7(b) and 7(c) show that the proportion of plastically deformed surface produced by particle shearing deformation increases with increasing cutting thickness, which also conforms to the theoretical predictions shown Figure 5(e). Hence, the machined surface quality can be improved with increasing cutting thickness, as presented in Figure 3(a).

(3) Machined Surface Morphology Obtained at Different Rake Angles. Figure 8 shows the morphologies of machined surfaces obtained at the rake angles of $-20^{\circ},-5^{\circ}$, and $15^{\circ}$, with a cutting thickness of $0.2 \mathrm{~mm}$. It can be seen that the surface quality machined at the rake angle of $-20^{\circ}$ is the best and that at the rake angle of $15^{\circ}$ is the worst. According to the cutting principle, when the rake angle increases from $-20^{\circ}$ to $20^{\circ}$, the rounded edge radius gradually decreases. Thus, the reason for this variation is that the proportion of ploughing and extruding is decreased due to the reduction in the rounded edge radius, which is shown in Figure 5(f). Therefore, the machined surface quality could be improved slightly by increasing the rake angle, as presented in Figure 3(c).

It should be pointed out that, in a similar study of ceramic green machining, the machined surface morphology created by Sanchez et al. [23] is better than the machined surface morphology of this paper. Apart from the different material types, another important reason is that the cutting speed used by Sanchez et al. was $78.5 \mathrm{~m} / \mathrm{min}$, which is much higher than the cutting speed used in this paper. Clearly, it is of great significance to further improve the machined surface finish of PM green compacts. According to the cutting principle, it can be predicted that when turning at a much higher cutting speed is adopted, the machined surface morphology of PM green compacts will be significantly improved. In addition, the research on ceramic green machining operated by Bukvic et al. [24] shows that sintering will reduce the machined surface roughness of green compacts. Moreover, the greater the surface roughness of green machined specimens, the greater the reduction rate will be after sintering. Therefore, the optimized sintering process may further improve the machined surface finish of PM green compacts.

4.3.2. Model Validation in Terms of Chip Morphology. Figure 9 shows the chip morphologies obtained with a cutting thickness of $0.2 \mathrm{~mm}$ and rounded edge radius of $20 \mu \mathrm{m}$. In Figure 9(a), the size distributions of the particle chips are identical with the values that are listed in Table 2. It is clearly suggested that there are numerous material removal trails of particles peeling off during the PM greenmachining process. Moreover, some plastic chips are also observed, as shown in Figure 9(b). These results validate that the material removal mode of particle shearing is objective.

A comparison of the polycrystalline $\mathrm{ZnSe}$ zinc sulfide chips during the precision machining process shows that the chips are irregularly granular due to brittle fracturing and larger block chips are formed by crack propagation [22]. The difference in chip shape indicates that the PM green compacts show a different material removal mechanism than the polycrystalline materials. Furthermore, it should be noted that the cutting mechanism of the PM green compacts is completely different from that of the ceramic green compacts. Sanchez et al. [23] observed the chip morphology of the ceramic green compacts, and the results showed that the chips were mainly in the powder form in small agglomerates of random shapes different than those of the initial powder. Therefore, the material removal mechanism of PM green machining is completely different from that of ceramic green machining. 


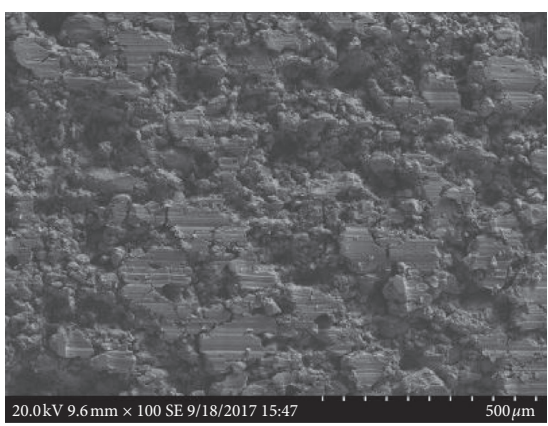

(a)

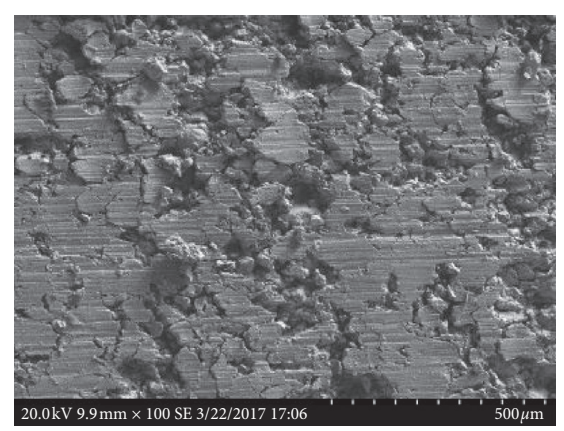

(b)

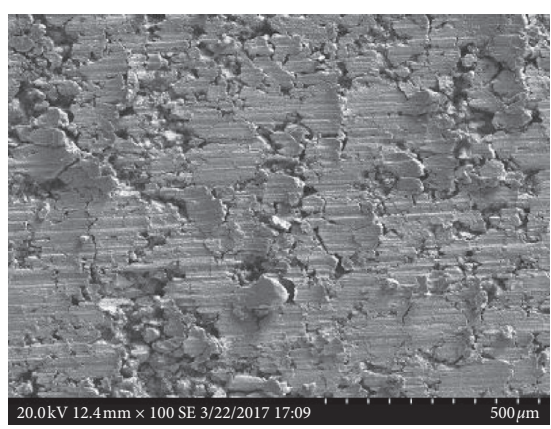

(c)

FIgURE 7: Machined surface morphologies produced with cutting thicknesses of (a) $0.05 \mathrm{~mm}$, (b) $0.14 \mathrm{~mm}$, and (c) $0.26 \mathrm{~mm}$.

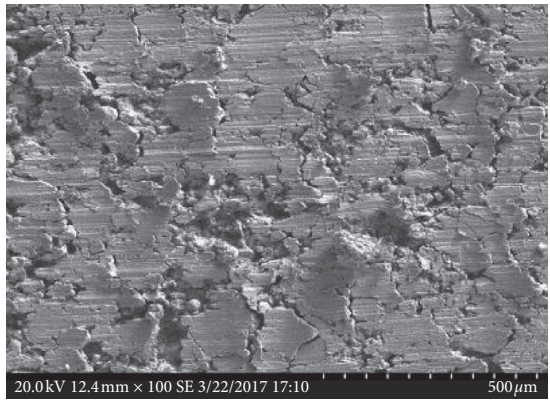

(a)

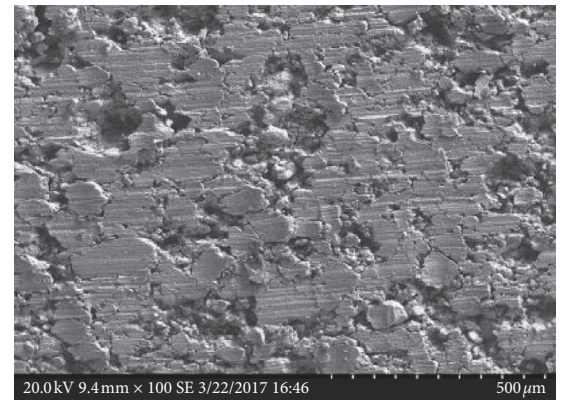

(b)

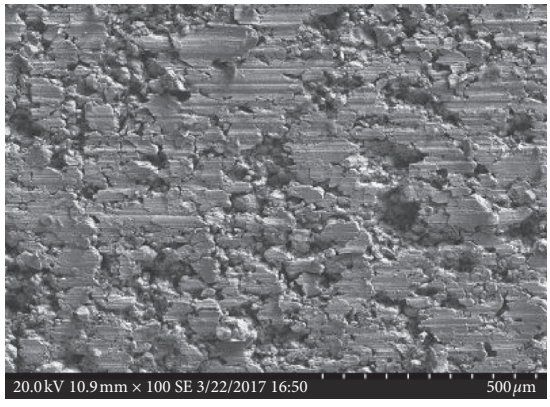

(c)

Figure 8: Machined surface morphologies machined at rake angles of (a) $-20^{\circ}$, (b) $-5^{\circ}$, and (c) $15^{\circ}$.

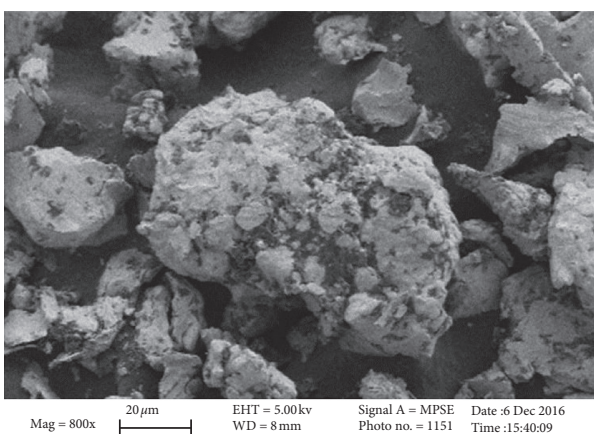

(a)

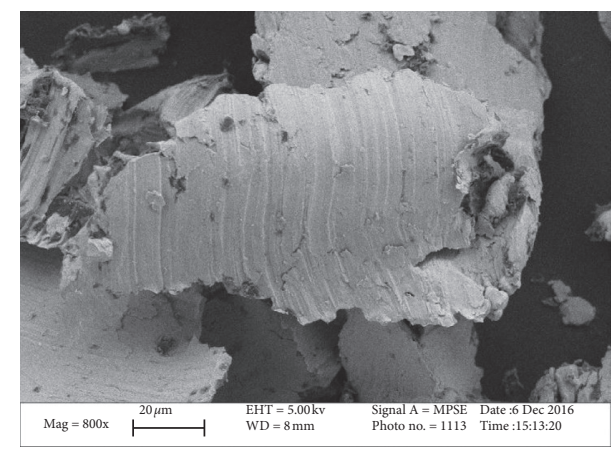

(b)

Figure 9: Chip morphologies formed by means of (a) particle peeling off and (b) shear deformation.

Overall, the material removal mechanism of PM compacts is well validated by machined surface morphologies and chip morphologies. In the process of PM green machining, the formation of the machined surface is the result of the combined action of three material removal modes. If the proportion of particle peeling off increases, the quality of the machined surface will deteriorate. The increasing proportion of particle shearing or ploughing and extruding will improve the quality of the machined surface.

\section{Conclusions}

(1) The machined surface morphology of PM green compacts is composed of plastically deformed surfaces, concavities, and crevices. The machined surface roughness apparently decreases with increasing cutting thickness and slightly increases with increasing rake angle. When the rounded cutting edge radius is less than $60 \mu \mathrm{m}$, the machined surface roughness decreases significantly 
and then slightly decreases with increasing rounded cutting edge radius.

(2) A geometric model of the PM green-machining process is proposed based on the representative machined surface morphologies. The mode of material removal for the green PM compacts can be characterized by particle shearing deformation, peeling off, and ploughing/extruding.

(3) When the cutting thickness and rounded cutting edge radius are small, the particle peeling off action is the main mode of material removal. As the cutting thickness and rounded cutting edge radius increase, the particle shearing and particle ploughing and extruding gradually become predominant gradually.

\section{Data Availability}

The digital data used to support the findings of this study are available from the corresponding author upon request.

\section{Conflicts of Interest}

The authors declare that there are no conflicts of interest regarding the publication of this paper.

\section{Acknowledgments}

This work was supported by the National Natural Science Foundation of China (no. 51775198), Science and Technology Project of Guangxi, China (no. GK AD19245149), and Science and Technology Project of Liuzhou, China (no. 2019DH10601).

\section{References}

[1] G. B. Jang, M. D. Hur, and S. S. Kang, "A study on the development of a substitution process by powder metallurgy in automobile parts," Journal of Materials Processing Technology, vol. 100, no. 1-3, pp. 110-115, 2000.

[2] J. Jiang, J. Yang, T. Zhang et al., "Microstructurally sensitive crack nucleation around inclusions in powder metallurgy nickel-based superalloys," Acta Materialia, vol. 117, pp. 333-344, 2016.

[3] M. Nezafati, I. Sohn, J. B. Ferguson, J.-S. Park, K. Cho, and C.-S. Kim, "DFT study on the adsorption and absorption behaviors of liquid nitrogen in the Mg nano alloys synthesized from powder metallurgy," Computational Materials Science, vol. 105, pp. 18-26, 2015.

[4] M. Dehestani, E. Adolfsson, and L. A. Stanciu, "Mechanical properties and corrosion behavior of powder metallurgy ironhydroxyapatite composites for biodegradable implant applications,” Materials \& Design, vol. 109, pp. 556-569, 2016.

[5] H. S. Jailani, A. Rajadurai, B. Mohan, and T. Sornakumar, "Sliding wear behaviour of Al-Si alloy-fly ash composites produced by powder metallurgy technique," Industrial $\mathrm{Lu}$ brication \& Tribology, vol. 69, no. 2, pp. 241-247, 2017.

[6] M. Czampa, I. Biró, and T. Szalay, "A novel machinability test for determining the cutting behaviour of iron-based, carboncontaining and copper-containing powder metallurgy steels (PMS)," The International Journal of Advanced Manufacturing Technology, vol. 89, no. 9-12, pp. 3495-3507, 2017.
[7] A. Salak, M. Selecka, and H. Danninger, Machinability of Powder Metallurgy Steels, Cambridge International Science Publishing, Cambridge, UK, 2005.

[8] D. S. Madan, "The importance of machinability in the processing of P/M parts," Advances in Powder Metallurgy \& Particulate Materials, vol. 2, 1995.

[9] Y. Qiao, Ai Xing, J. Zhao, and L. Zhan-qiang, "Failure mechanism of coated carbide tools in milling of nickelbase powder metallurgy superalloy," Journal of Beijing University of Technology, vol. 37, no. 1, pp. 1-6, 2011.

[10] Du. Jin and Z. Liu, "Effect of cutting speed on surface integrity and chip morphology in high-speed machining of PM nickel-based superalloy FGH95," The International Journal of Advanced Manufacturing Technology, vol. 60, no. 9-12, pp. 893-899, 2012.

[11] R. M'saoubi, T. Czotscher, O. Andersson, and D. Meyer, "Machinability of powder metallurgy Steels using PcBN inserts," Procedia CIRP, vol. 14, pp. 83-88, 2014.

[12] H. Kulkarni and V. V. Dabhade, "Green machining of powder-metallurgy-steels (PMS): an overview," Journal of Manufacturing Processes, vol. 44, pp. 1-18, 2019.

[13] J. Desbiens, E. Robert-Perron, C. Blais, and F. Chagnon, "Effect of green machining on the tensile properties and fatigue strength of powder metallurgy sinter-hardenable steel components," Materials Science and Engineering: A, vol. 546, no. 3, pp. 218-222, 2012.

[14] E. Robert-Perron, C. Blais, S. Pelletier, and Y. Thomas, "Machinability of green powder metallurgy components: part ii. Sintered properties of components machined in green state," Metallurgical and Materials Transactions A, vol. 38, no. 6, pp. 1337-1342, 2007.

[15] E. Robert-Perron, C. Blais, S. Pelletier, Y. Thomas, and S. St-Laurent, "Chip reclamation in green machining for high-performance PM components," International Journal of Powder Metallurgy, vol. 43, no. 3, pp. 49-55, 2007.

[16] E. Robert-Perron, C. Blais, Y. Thomas, S. Pelletier, and M. Dionne, "An integrated approach to the characterization of powder metallurgy components performance during green machining," Materials Science and Engineering: $A$, vol. 402, no. 1-2, pp. 325-334, 2005.

[17] E. Robert-Perron, C. Blais, S. Pelletier, and Y. Thomas, "Drilling of high quality features in green powder metallurgy components," Materials Science \& Engineering A, vol. 458, no. 1-2, pp. 195-201, 2007.

[18] M. Gagné and F. Chagnon, "Characterizing machinability of green PM parts," Metal Powder Report, vol. 55, no. 10, p. $48,2000$.

[19] L. Tremblay, F. Chagnon, Y. Thomas, and M. Gagné, "Green machining of $\mathrm{P} / \mathrm{M}$ parts using enhanced green strength lubricating systems," SAE Technical Paper, vol. 399, no. 1, pp. 53-61, 2001.

[20] L. Tremblay, F. Chagnon, and Y. Thomas, "Enhancing green strength of $\mathrm{P} / \mathrm{M}$ materials," Advances in Powder Metallurgy \& Particulate Materials, vol. 3, pp. 129-141, 2001.

[21] F. Chagnon, L. Tremblay, S. St-Laurent, and M. Gagné, "Improving green strength to enable green machining," Sae Technical Papers, vol. 337, no. 1, pp. 71-76, 1999.

[22] W. Huang and J. Yan, "Surface formation mechanism in ultraprecision diamond turning of coarse-grained polycrystalline ZnSe," International Journal of Machine Tools and Manufacture, vol. 153, Article ID 103554, 19 pages, 2020.

[23] L. E. A. Sanchez, G. Bukvic, C. A. Fiocchi, and C. A. Fortulan, "Allowance removal from green pieces as a method for 
improvement surface quality of advanced ceramics," Journal of Cleaner Production, vol. 186, no. 10, pp. 10-21, 2018.

[24] G. Bukvic, L. E. d. A. Sanchez, C. A. Fortulan, A. A. Fiocchi, I. D. Marinescu, and I. D. Marinescu, "Green machining oriented to diminish density gradient for minimization of distortion in advanced ceramics," $M a-$ chining Science and Technology, vol. 16, no. 2, pp. 228-246, 2012. 